\title{
Education and Supplementation to Overcome Malnutrition in Pregnant Mothers for Improving Offspring Development
}

\author{
Teresa Arora* and Ayesha Salem-Al Murry \\ Department of Psychology, Zayed University, United Arab Emirates
}

${ }^{*}$ Corresponding author: Teresa Arora, Department of Psychology, College of Natural and Health Sciences, Zayed University, Abu Dhabi, United Arab Emirates

Submission: 泟June 02, 2018; Published: 啙June 08, 2018

\section{Introduction}

The pre-natal environment as well as the health of women during pregnancy is vital to the survival, health, development, growth and longevity of their offspring. Taking folic acid before and during pregnancy has been shown to help prevent fetal birth defects of the central nervous system, specifically neural tube defects [1]. Developing countries have an extraordinary high level of stunted growth rates in children. Evidence suggests that this is the result of malnutrition during the mother's pregnancy, as well as in the infant, up to three years after delivery. Stunted growth in children and low birth weight are major public health challenges and these are therefore a national priority in some developing countries. In particular, great efforts have been made to address this problem in several parts of Africa where lipid-based nutrient supplements have been provided to pregnant and lactating women as well as for their offspring in order to promote the healthy development of children.

In this edition of the Global Journal of Endocrinological Metabolism, Ombogo and colleagues report on research findings from a trial [2], which compared growth rates of offspring in two groups: 1) Pregnant women who were provided with a small quantity of lipid-based nutrient supplements as well as iron and folic acid; 2) Pregnant women who were provided with iron and folic acid supplementation (control group). Both groups of pregnant women were provided with the supplementations throughout their pregnancy and continued six months post-partum. Findings of the study revealed promising results with babies being born to mothers in group 1 having significantly higher birth weights and lengths as well as head circumference, length-for-age z-score, weight-for-age z-score, head circumference-for-age z-score, and body mass index z-score. Although some of these findings were small, they are important and provide a knowledge and evidencebase surrounding the importance of the in-utero environment for subsequent paediatric development. In particular, there was a $17 \%$ significant reduction in the prevalence of stunting in new born babies as well as a significant reduction in the number of babies with small head size and low BMI immediately after delivery. The authors concluded that this was largely attributed to those receiving and ingesting small quantity lipid-based nutrient supplements paired with iron and folic acid, given that there was a $25 \%$ reduction in stunted babies compared to mothers who received iron and folic acid supplements.

Besides the nutrition of pregnant women, the authors could have also considered the possible effect of maternal sleep upon outcomes of interest. For example, a recent study showed that impaired sleep during pregnancy increased the risk of metabolic dysfunction (gestational diabetes mellitus [GDM]) in Asian mothers [3]. This finding is of particular importance given the well documented effects of GDM on birth weight [4] and subsequent weight gain and obesity in adolescence [5]. At face value, these findings may be more relevant to developed countries where pregnant women are more likely to have excess adiposity, in comparison to those residing in developing countries that are more likely to have low body mass index due to malnutrition. However, sleep behaviour is likely to be an important contributor to maternal health, regardless of the body weight of the mother, as well as development of the fetus in-utero. Sleep restriction during pregnancy has been linked to neuro developmental dysfunction [6] and later behavioural issues [7] in animal models. The evidence surrounding the effects of maternal sleep on the development of children in humans is scarce. One recent study showed that pregnant women with short sleep duration were more likely to have premature babies and that long sleep duration was associated with lower birth weight z-scores [8]. A systematic review identified six studies relating to labour and delivery, eight articles surrounding preterm birth and three articles concerning birth weight and growth [9]. The authors concluded that sleep insufficiency in expectant mothers was linked to a range of adverse pregnancy out comes [9]. Interestingly, sleep has also been linked to energy homeostasis $[10,11]$ thus sleep may mediate the effects of maternal malnutrition on offspring growth 
and development. Although further work in this area needs to be conducted, sleep behaviour in pregnancy is likely to play an important role in child development.

The multiple findings reported by Ombogo et al. [2] are of great importance given the statistics surrounding growth stunting in developing countries. Small efforts to overcome malnutrition in pregnant mothers will not only help to ensure healthy development of the next generation, but will also minimize the risk of developing other diseases. This, in turn, will improve health outcomes and extend longevity. Resources and funding are clearly needed to help educate and supplement individuals in developing countries to support basic human needs such as nutrition and a comfortable sleep environment.

\section{References}

1. De-Regil LM, Pena-Rosas JP, Fernandez-Gaxiola AC, Rayco-Solon P (2015) Effects and safety of periconceptional oral folate supplementation for preventing birth defects. Cochrane Database Syst Rev (12): CD007950.

2. Ombogo J, Konyole S, Nguka G, Musau K, Kiprotich M (2018) Effectiveness of nutrition/health behavior change communication training; micronutrient supplementation and lipid-nutrient supplements to improve child health in western kenya. Global Journal of Endocrinological Metabolism 2(2): 1-11.

3. Cai S, Tan S, Gluckman PD, Godfrey KM, Saw SM, et al. (2017) Sleep quality and nocturnal sleep duration in pregnancy and risk of gestational diabetes mellitus. Sleep 40(2).
4. Kim SY, Sharma AJ, Sappenfield W, Wilson HG, Salihu HM (2014) Association of maternal body mass index, excessive weight gain, and gestational diabetes mellitus with large-for-gestational-age births. Obstet Gynecol 123(4): 737-744.

5. Gillman MW, Rifas-Shiman S, Berkey CS, Field AE, Colditz GA (2003) Maternal gestational diabetes, birth weight, and adolescent obesity. Pediatrics 111(3): e221-e226.

6. Pardo GV, Goularte JF, Hoefel AL, De Castro AL, Kucharski LC, et al. (2016) Effects of sleep restriction during pregnancy on the mother and fetuses in rats. Physiol Behav 155: 66-76.

7. Radhakrishnan A, Aswathy BS, Kumar VM, Gulia KK (2015) Sleep deprivation during late pregnancy produces hyperactivity and increased risk-taking behavior in offspring. Brain Res 1596: 88-98.

8. Plancoulaine S, Flori S, Bat-Pitault F, Patural H, Lin JS, et al. (2017) Sleep trajectories among pregnant women and the impact on outcomes: a population-based cohort study. Matern Child Health J 21(5): 1139-1146.

9. Palagini L, Gemignani A, Banti S, Manconi M, Mauri M, et al. (2014) Chronic sleep loss during pregnancy as a determinant of stress: impact on pregnancy outcome. Sleep Med 15(8): 853-859.

10. Klingenberg L, Sjodin A, Holmback U, Astrup A, Chaput JP (2012) Short sleep duration and its association with energy metabolism. Obes Rev 13(7): 565-577.

11. St-Onge MP (2013) The role of sleep duration in the regulation of energy balance: effects on energy intakes and expenditure. J Clin Sleep Med $9(1): 73-80$
Creative Commons Attribution 4.0

International License

For possible submissions Click Here

\section{Submit Article}

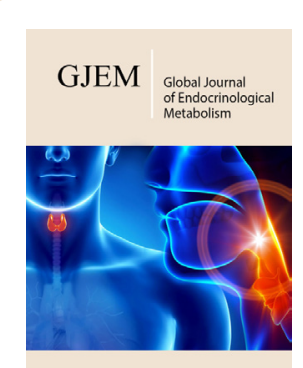

Global Journal of Endocrinological Metabolism

\section{Benefits of Publishing with us}

- High-level peer review and editorial services

- Freely accessible online immediately upon publication

- Authors retain the copyright to their work

- Licensing it under a Creative Commons license

- Visibility through different online platforms 